\title{
Histological Studies of the Effects of Monosodium Glutamate on the Stomach in Adult Rats
}

\author{
Zuhair M Mohammedsaleh ${ }^{1,2^{*}}$ and Gamal Abd El- Aziz ${ }^{2}$ \\ ${ }^{1}$ Faculty of Applied Medical Sciences, University Of Tabuk, Tabuk, Kingdom of Saudi Arabia \\ ${ }^{2}$ Faculty of Medicine, King Abdulaziz University, Jeddah, Saudi Arabia
}

"Corresponding author: Zuhair Mohammedsaleh, Faculty of Applied Medical Sciences, University Of Tabuk, Tabuk, Kingdom of Saudi Arabia, Tel: +966504303999; Email: zuhair.saleh966@gmail.com

Rec date: Aug 12, 2014, Acc date: Aug 14, 2014, Pub date: Aug 23, 2014

Copyright: (c) 2014 Mohammedsaleh ZM. This is an open-access article distributed under the terms of the Creative Commons Attribution License, which permits unrestricted use, distribution, and reproduction in any medium, provided the original author and source are credited.

\section{Introduction}

This is the part of the project: Master of Science (MS) in Technical Anatomy \& Histology King Abdul-Aziz University, Jeddah, Saudi Arabia. 2009. The safety of monosodium glutamate (MSG) usage as a food additive has generated much controversy locally and globally. The effect of MSG on the stomach of adult Wistar rat was investigated. Fifteen adult male Wistar rats of average weight of 175-200 grams were used in this study and randomly assigned into two treatments $(n=6)$ and control $(n=3)$ groups. The rats in the treatment groups received 3 and $6 \mathrm{gm} / \mathrm{Kg}$ body weight of MSG thorough oral route daily for seven days. The control rats received equal amounts of distilled water. The rats were sacrificed after seven days of the experiment. The stomach were carefully dissected out and quickly fixed in $10 \%$ formol saline for routine histological procedures. Regarding the stomach, the histological findings in the treated groups showed evidence of increased inflammatory cellular infiltration and cellular hypertrophy in animals given $3 \mathrm{gm}$ of MSG, while degenerative, atrophic changes and increased amounts of connective tissues around the bases of the gastric glands and in the submucosa in the group with $6 \mathrm{gm}$. These findings indicate that MSG may have some deleterious effects on the microanatomy of the stomach of adult Wistar rats at higher doses. It is recommended that further studies aimed at corroborating these findings be carried out.

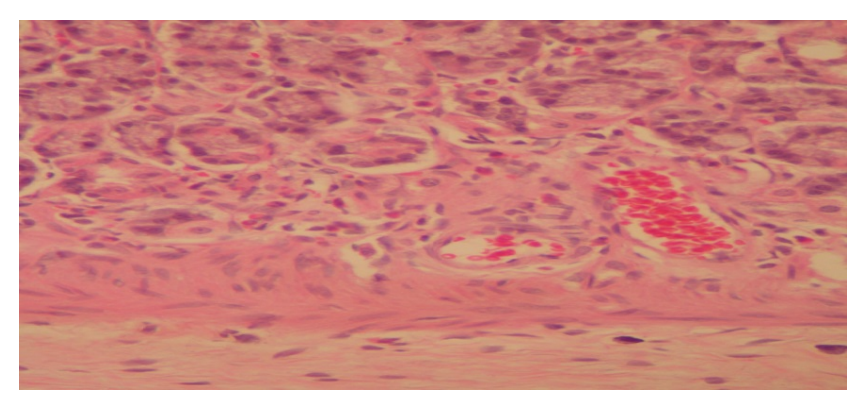

Figure 1: Photomicrograph of a section of the stomach of rats which received low dose of MSG showing multiple congested blood vessels (bv) in the gastric submucosa.

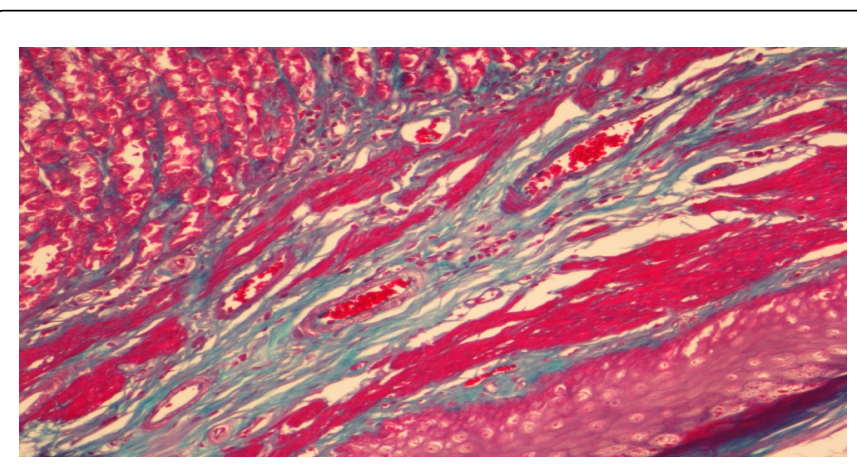

Figure 2: Photomicrograph of a section of the body of stomach of rats which received large dose of MSG showing increase of connective tissues lamina propria and around the basal parts of the gastric gland. Masson's trichrome 400X. 